\title{
Diazafluorenone-Promoted Oxidation Catalysis: Insights into the Role of Bidentate Ligands in Pd-Catalyzed Aerobic Aza-Wacker Reactions
}

\author{
Paul B. White, Jonathan N. Jaworski, Geyunjian Harry Zhu, and Shannon S. Stahl ${ }^{\star}$ \\ Department of Chemistry, University of Wisconsin-Madison, 1101 University Avenue, Madison, WI \\ 53706
}

\section{Abstract}

2,2'-Bipyridine (bpy), 1,10-phenanthroline (phen) and related bidentate ligands often inhibit homogeneous Pd-catalyzed aerobic oxidation reactions; however, certain derivatives, such as 4,5diazafluoren-9-one (DAF), can promote catalysis. In order to gain insight into this divergent ligand behavior, eight different bpy- and phen-derived chelating ligands have been evaluated in $\operatorname{Pd}(\mathrm{OAc})_{2}$-catalyzed oxidative cyclization of $(E)$-4-hexenyltosylamide. Two of the ligands, DAF and 6,6'-dimethyl-2,2'-bipyridine (6,6'- $\left.\mathrm{Me}_{2} \mathrm{bpy}\right)$, support efficient catalytic turnover, while the others strongly inhibit the reaction. DAF is especially effective and is the only ligand that exhibits "ligand-accelerated catalysis". Evidence suggests that the utility of DAF and 6,6'-Me 2 bpy originates from the ability of these ligands to access $\kappa^{1}$-coordination modes via dissociation of one of the pyridyl rings. This hemilabile character is directly observed by NMR spectroscopy upon adding one equivalent of pyridine to solutions of 1:1 $\mathrm{L} / \mathrm{Pd}(\mathrm{OAc})_{2}\left(\mathrm{~L}=\mathrm{DAF}\right.$ and 6,6'-Me $\left.\mathrm{Me}_{2} \mathrm{bpy}\right)$, and is further supported by an X-ray crystal structure of $\mathrm{Pd}(\mathrm{py})\left(\kappa^{1}-\mathrm{DAF}\right) \mathrm{OAc} \mathrm{c}_{2}$. DFT computational studies illuminate the influence of three different chelating ligands [DAF, 6,6'-Me 2 bpy, and 2,9dimethyl-1,10-phenanthroline (2,9-Me 2 phen)] on the energetics of the aza-Wacker reaction pathway. The results show that DAF and 6,6'- $\mathrm{Me}_{2}$ bpy destabilize the corresponding ground-state $\mathrm{Pd}(\mathrm{N} \sim \mathrm{N})(\mathrm{OAc})_{2}$ complexes, while stabilizing the rate-limiting transition state for alkene insertion into a Pd-N bond. Interconversion between $\kappa^{2}$ - and $\kappa^{1}$-coordination modes facilitate access to open coordination sites at the $\mathrm{Pd}^{\mathrm{II}}$ center. The insights from these studies introduce new ligand concepts that could promote numerous other classes of Pd-catalyzed aerobic oxidation reaction.

\section{Graphical Abstract}

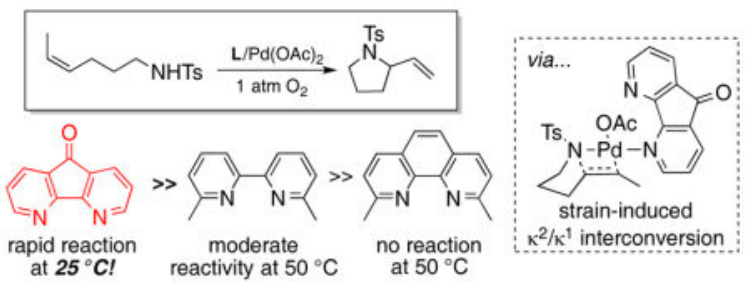

*Corresponding Author: stahl@chem.wisc.edu.

Supporting Information. Experimental and computational details, NMR spectra and crystallography reports are available free of charge via the Internet at http://pubs.acs.org. 


\section{Keywords}

palladium; aerobic; oxidation; catalysis; mechanism; Wacker; diazafluorenone

\section{Introduction}

The discovery of ligand-modulated palladium(II) catalysts has played a major role in the growth of homogeneous palladium-catalyzed aerobic oxidation reactions over the past 15+ years. ${ }^{1,2}$ Ancillary ligands often provide the basis for dioxygen-coupled catalytic turnover without requiring cocatalysts or other stoichiometric oxidants, such as benzoquinone or $\mathrm{Cu}^{\mathrm{II}}$ salts. Synthetic and mechanistic studies of these reactions highlight multiple roles of the ligands in this chemistry (Scheme 1). The ligands play a crucial role in stabilizing the catalyst ${ }^{3}$ and promoting reoxidation of $\mathrm{Pd}^{0}$ by $\mathrm{O}_{2}$ (Scheme 1: $a$ and $c$ ). ${ }^{4,5}$ Ligands also enable control over reaction selectivity, prominent examples of which include kinetic resolution of secondary alcohols, ${ }^{6}$ and regio- ${ }^{7}$ and enantioselective ${ }^{8}$ oxidative Heck reactions. But, the role of ligands is not always beneficial. Ligands often inhibit catalytic turnover or slow the rate by attenuating the electrophilicity of the $\mathrm{Pd}^{\mathrm{II}}$ center and/or occupying open coordination sites needed for substrate oxidation. The characteristics of ligands that contribute to favorable, rather than deleterious, effects are not well understood, and insights into such factors could have a major impact on the field. ${ }^{9}$

Pyridine (py)-based ligands are widely used in Pd-catalyzed aerobic oxidation reactions. ${ }^{1,2}$ In one of the earliest examples, Uemura and coworkers reported that $\mathrm{Pd}(\mathrm{OAc})_{2} / \mathrm{py}(1: 4$ ratio) is a highly effective catalyst for aerobic alcohol oxidation (eq 1). ${ }^{10}$ Upon finding that a similar catalyst system, $\mathrm{Pd}(\mathrm{OAc})_{2} /$ py $(1: 2$ ratio), mediates efficient intramolecular oxidative amination of alkenes (eq 2; aza-Wacker reactions), ${ }^{11}$ we undertook mechanistic studies of these reactions to gain insight into the ligand effects. ${ }^{5 e, 12}$ In the alcohol oxidation reaction, $\mathrm{Pd}(\mathrm{OAc})_{2}$ shows no catalytic turnover in the absence of pyridine. The initial catalytic rate maximizes at 1:1 $\mathrm{Pd}(\mathrm{OAc})_{2} / \mathrm{py}$; however, catalyst decomposition into Pd black limits the total turnover numbers. The catalyst is less active but more stable at higher [py], and the optimized 1:4 $\mathrm{Pd}(\mathrm{OAc})_{2} /$ py catalyst system represents the compromise between catalyst activity and stability that achieves the highest synthetic yields. ${ }^{10 b}$ Related pyridine effects were observed for the aza-Wacker reaction, with the optimal balance observed with a 1:2 $\mathrm{Pd}(\mathrm{OAc})_{2} /$ py catalyst system. ${ }^{12 \mathrm{c}, 13}$

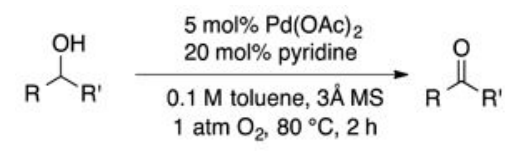




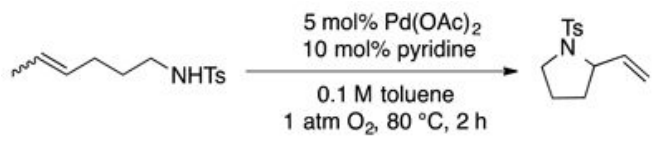

(2)

Bidentate ligands, such as 2,2'-bipyridine (bpy) and phenanthroline (phen), are appealing ligands to consider for Pd-catalyzed aerobic oxidation reactions because their chelating ability should enhance the stability of $\mathrm{Pd}^{0}$ and promote its oxidation by $\mathrm{O}_{2}$ (cf. Scheme 1). But, bpy and phen strongly inhibit the reactions shown in eqs 1 and 2, ${ }^{10,14}$ and similar inhibitory effects have been observed in numerous other reactions. ${ }^{15,16} \mathrm{In}$ an investigation of aerobic acetoxylation of allylic $\mathrm{C}-\mathrm{H}$ bonds, ${ }^{17}$ we observed negligible catalytic activity with $\mathrm{Pd}(\mathrm{OAc})_{2}$, both in the absence of an ancillary ligand and in the presence of pyridine or numerous bpy and phen ligand derivatives (eq 3 ). The sole exception was 4,5diazafluoren-9-one (DAF). DAF/Pd(OAc) $)_{2}$ proved to be an effective catalyst for aerobic allylic $\mathrm{C}-\mathrm{H}$ acetoxylation of allyl benzene and numerous other terminal alkene substrates. Subsequent studies have shown that DAF is uniquely effective in a number of other Pdcatalyzed aerobic oxidation reactions, including oxidative $\mathrm{C}-\mathrm{C}$ and $\mathrm{C}-\mathrm{O}$ coupling reactions with arenes, ${ }^{18}$ a, $\beta$-dehydrogenation of cyclic ketones, ${ }^{19}$ oxidative Heck reactions, ${ }^{20}$ and also various non-aerobic oxidation reactions. ${ }^{21}$

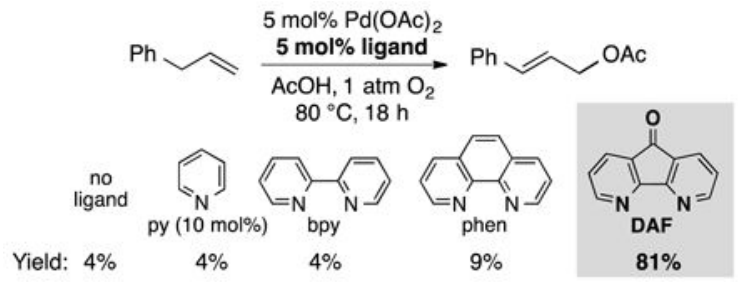

The basis for the unique effect of DAF in eq 3 and the other reactions is not well understood. In a recently completed study, ${ }^{22}$ we characterized six different complexes, including both monomeric and dimeric species, that are simultaneously present in a 1:1 mixture of DAF and $\mathrm{Pd}(\mathrm{OAc})_{2}$ (Chart 1). The complex coordination chemistry of DAF ${ }^{23}$ sharply contrasts the behavior of other bidentate ligands, such as bpy and phen, which form 1:1 adducts as the sole structure in solution. The unique ligand behavior of DAF correlates with the unique catalytic behavior noted above, but the mechanistic basis for the catalytic effects has not been established.

In an effort to gain further insights into the role of DAF, we decided to revisit the reactivity of bidentate ligands in Pd-catalyzed aza-Wacker reactions. This reaction class is one of the most extensively studied among Pd-catalyzed aerobic oxidations, with efforts leading to the identification of numerous catalyst systems, synthetic applications, and mechanistic insights. ${ }^{24,25}$ These precedents provide an excellent framework for the investigation of 
ligand contributions to reactivity. Here, we show that whereas most bidentate ligands strongly inhibit catalytic turnover, both DAF and 6,6'-dimethyl-2,2'-bipyridine (6,6'- $\mathrm{Me}_{2}$ bpy) support reactivity. Only DAF, however, exceeds the utility of pyridine and exhibits "ligand accelerated catalysis". Kinetic, spectroscopic, X-ray crystallographic, and DFT computational studies show that DAF and 6,6'- $\mathrm{Me}_{2}$ bpy exhibit hemilabile behavior in solution. The collective data provide valuable insights into ligand properties that promote efficient catalytic turnover and have broad implications for the field of Pd-catalyzed aerobic oxidation, as well as other catalytic applications.

\section{Results and Discussion}

\section{Comparison of Ligand Effects on Pd-Catalyzed Aerobic Aza-Wacker Reactivity}

4-Alkenyltosylamides (cf. eq 2) have been widely used for the development of new Pd catalyst systems ${ }^{26}$ and characterization of catalytic mechanisms. ${ }^{27}$ Therefore, cis-4hexenyltosylamide (1) was chosen to assess the influence of bidentate ligands on aerobic aza-Wacker reactivity. A broad series of bpy and phen derivatives were evaluated in this reaction at $50{ }^{\circ} \mathrm{C}$ under conditions similar to those described previously with the $\mathrm{Pd}(\mathrm{OAc})_{2} /$ py-catalyst system (Table 1$)$. Ligand-free $\mathrm{Pd}(\mathrm{OAc})_{2}$ and the $\mathrm{Pd}(\mathrm{OAc})_{2} /$ py were included for comparison. ${ }^{28}$ The ligand-free conditions (entry 1 ) give a moderate product yield, but poor mass balance. By-products were not fully characterized, but sulfonyl imine and its aldehyde hydrolysis product are detected. In contrast, $\mathrm{Pd}(\mathrm{OAc})_{2}$ /py catalyzes clean conversion to the pyrrolidine product in $86 \%$ yield (entry 2). ${ }^{11}$ Use of four different phen derivatives, 4,4'- $\mathrm{Bu}_{2}$ bpy, and bipyrimidine (entries 3-8) resulted in nearly complete inhibition of the reaction (yield $\leq 10 \%$ ). Use of 2,2'-dipyridyl ketone and 6-Mebpy resulted led to a moderate yield ( $26 \%$ and $38 \%$, respectively; entries 9 and 10), however, and the yield improved considerably upon use of $6,6^{\prime}-\mathrm{Me}_{2}$ bpy $(81 \%$, entry 11$)$. The best results were observed with 9,9-dimethyl-4,5-diazafluorene ( $\left.\mathrm{Me}_{2} \mathrm{DAF}\right)$ and DAF, which led to nearquantitative yield (92\% and 97\%, respectively; entries 12 and 13). The relative effects of 6,6'- $\mathrm{Me}_{2}$ bpy and the DAF derivatives were further analyzed at room temperature. Under these conditions, $\mathrm{Me}_{2} \mathrm{DAF}$ and DAF proved to be quite effective, again affording excellent yield (92\% and 97\%, respectively), whereas a considerably lower yield was observed with 6,6'- $\mathrm{Me}_{2}$ bpy (40\%). That all reactions except the ligand-free reaction exhibited excellent mass balance highlights the beneficial effect of ligands on reaction chemoselectivity. A number of traditional bidentate ligands strongly inhibit catalytic reactivity, but this preliminary screen also shows that certain bidentate ligands, specifically, 6,6'- $\mathrm{Me}_{2} \mathrm{bpy}$, $\mathrm{Me}_{2} \mathrm{DAF}$ and DAF, match or exceed the performance of pyridine.

Reaction time-course studies performed with selected ligands at $50{ }^{\circ} \mathrm{C}$ provided further insight into the ligand effects. Reactions with DAF, 6,6'- $\mathrm{Me}_{2}$ bpy and the structurally related 2,9- $\mathrm{Me}_{2}$ phen ligand were compared to the ligand-free and $\mathrm{Pd}(\mathrm{OAc})_{2} /$ py-catalyzed reactions (Figure 1). ${ }^{29}$ The latter benchmark reactions exhibit similar rates of substrate consumption, and the reaction with 6,6'- $\mathrm{Me}_{2}$ bpy is only moderately slower. The impact of the moderately slower rates observed with pyridine and 6,6'- $\mathrm{Me}_{2}$ bpy relative to the ligand-free conditions is offset by the improved mass balance/reaction selectivity observed in the presence of these ligands, as manifested in the product yields obtained from the reactions (cf. Table 1). 2,9- 
$\mathrm{Me}_{2}$ phen almost completely inhibits of the reaction, while the reaction with DAF is significantly faster than all of the other reactions. DAF enables complete conversion to the pyrrolidine product in approximately $1 \mathrm{~h}$, with excellent mass balance.

Next, the influence of $\mathrm{Pd}(\mathrm{OAc})_{2}$ :ligand stoichiometry on the catalytic reaction was evaluated (Figure 2). The pyridine data (Figure 2A) resemble those obtained previously under slightly different conditions. ${ }^{11 \mathrm{c}} \mathrm{A}$ modest increase in rate is observed from $0-1$ equiv of pyridine with respect to $\mathrm{Pd}(\mathrm{OAc})_{2}$. Beyond this stoichiometry, additional pyridine exhibits an inhibitory effect until it reaches a non-zero plateau at high [py]. The bidentate ligands 6,6'$\mathrm{Me}_{2}$ bpy and 2,9- $\mathrm{Me}_{2}$ phen inhibit $\mathrm{Pd}(\mathrm{OAc})_{2}$ in direct proportion to their stoichiometry with respect to $\mathrm{Pd}(\mathrm{OAc})_{2}$ (Figures $2 \mathrm{~B}$ and $2 \mathrm{C}$ ); however, 2,9- $\mathrm{Me}_{2}$ phen completely inhibits the reaction at $\geq 1$ equiv of ligand relative to $\mathrm{Pd}(\mathrm{OAc})_{2}$, while 6,6'- $\mathrm{Me}_{2}$ bpy/ $\mathrm{Pd}(\mathrm{OAc})_{2}$ retains moderate catalytic activity beyond 1:1 stoichiometry. The behavior of DAF is unique. No inhibitory effect is observed, even with a large excess of DAF (Figure 2D). This type of ligand-acceleration effect with a neutral-donor ligand is, to our knowledge, unprecedented in Pd-catalyzed aerobic oxidations.

\section{Ligand Coordination Properties and Relative Binding Strength}

As noted in the Introduction, DAF forms six nearly isoenergetic coordination compounds upon reaction with $\mathrm{Pd}(\mathrm{OAc})_{2}$ (cf. Chart 1). ${ }^{22}$ This unusual coordination chemistry was the focus of a recent study and was attributed to structural distortions of DAF relative to traditional bpy and phen ligands (Figure 3). Meanwhile, 6,6'- $\mathrm{Me}_{2}$ bpy and 2,9- $\mathrm{Me}_{2}$ phen also show unusual coordination behavior resulting from the steric clash between the methyl groups and other ligands in the square plane. An X-ray crystal obtained for $\mathrm{Pd}\left(6,6-\mathrm{Me}_{2}\right.$ bpy) $(\mathrm{OAc})_{2}$ (Figure 4A) highlights the distorted coordination geometry of this complex. The plane of the 6,6'- $\mathrm{Me}_{2}$ bpy ligand lies at a $33^{\circ}$ angle with respect to the $\mathrm{Pd}^{\mathrm{II}}$ square plane, which reduces the steric interaction between the two ligand methyl groups and the acetate ligands. Similar structural behavior has been reported previously for $\mathrm{Pd}\left(2,9-\mathrm{Me}_{2}\right.$ phen $)$ $(\mathrm{OAc})_{2}$, in which the phen ligand bends out of the square plane by $34^{\circ} .{ }^{30}$ One difference is evident between the 6,6'- $\mathrm{Me}_{2}$ bpy and 2,9- $\mathrm{Me}_{2}$ phen ligands: the 6,6'- $\mathrm{Me}_{2}$ bpy ligand exhibits an unfavorable steric interaction between the hydrogen atoms in the 3 and 3 ' positions (Figure 4B), whereas the phenanthroline ligand has a covalent $\mathrm{C}=\mathrm{C}$ bond in this position. This feature is believed to destabilize the binding of 6,6'-Me 2 bpy relative to 2,9-Me $\mathrm{Me}_{2} \mathrm{phen}$, as elaborated below.

An effort was made to assess the relative binding strength among 4,4'- ${ }^{\mathrm{t}} \mathrm{Bu}_{2}$ bpy, 2,9$\mathrm{Me}_{2}$ phen, 6,6'-Me 2 bpy, and DAF as ligands. Each of these ligands was combined with $\mathrm{Pd}(\mathrm{OAc})_{2}$ in a 1:1 ratio in $\mathrm{CDCl}_{3}$, and variable quantities of pyridine (0.5-5 equiv) were then added to these solutions (see Supporting Information, Figures S4-S7). ${ }^{31}$ The different mixtures were analyzed by ${ }^{1} \mathrm{H}$ NMR spectroscopy and, in all cases except with DAF, the sole species observed in solution were the $\mathrm{Pd}(\mathrm{N} \sim \mathrm{N})(\mathrm{OAc})_{2}$ adduct and trans-Pd(py $)_{2}(\mathrm{OAc})_{2}$. Mixtures of $\mathrm{Pd}(\mathrm{OAc})_{2}$, the $\mathrm{N} \sim \mathrm{N}$ ligand, and pyridine in 1:1:2 ratios provide a diagnostic assessment of the relative binding strengths of the different ligands (Table 2). With $4,4^{\prime}-{ }^{\mathrm{t}} \mathrm{Bu}_{2}$ bpy, negligible quantities of the pyridine complex were observed $(<3 \%)$. With $2,9-$ 
$\mathrm{Me}_{2}$ phen, the bidentate ligand complex was favored 5:1 over the pyridine adduct, while an

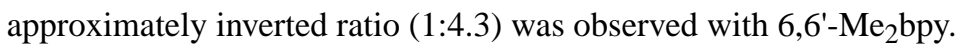

The DAF mixture was complicated at room temperature, but negligible contribution from the simple $\kappa^{2}$-DAF complex was evident. Broadened peaks implicated dynamic exchange processes, and the solution was cooled to $-35^{\circ} \mathrm{C}$ to facilitate characterization of the species in solution. Two major species were present: $\mathrm{Pd}(\mathrm{py})_{2}(\mathrm{OAc})_{2}$ and a new species, which was characterized by 1D and 2D NMR spectroscopic methods (including 1D TOCSY, 1D ROESY, ${ }^{1} \mathrm{H}_{-}{ }^{13} \mathrm{C}$ HSQC, ${ }^{1} \mathrm{H}_{-}{ }^{13} \mathrm{C} \mathrm{HMBC}$, and ${ }^{1} \mathrm{H}_{-}{ }^{15} \mathrm{~N}$ HMBC methods; see Supporting Information for details, Figures $\mathrm{S} 8 \mp \mathrm{S} 14)$. This species was identified as $\operatorname{Pd}\left(\kappa^{1}-\mathrm{DAF}\right)(\mathrm{py})$ $(\mathrm{OAc})_{2}$ and was present in a 1:5.4 ratio relative to $\mathrm{Pd}(\mathrm{py})_{2}(\mathrm{OAc})_{2}$. The identity of this complex was further established by X-ray crystallography (Figure 5). ${ }^{32}$

The room-temperature mixtures of $\mathrm{Pd}(\mathrm{OAc})_{2}, 6,6^{\prime}-\mathrm{Me}_{2}$ bpy and pyridine also showed some evidence for dynamic behavior, reflected by changes in the chemical shift of peaks associated with the 6,6'-Me 2 bpy as a function of the amount of pyridine in solution. As noted in Table 2, pyridine coordination is favored over coordination of $6,6^{\prime}-\mathrm{Me}_{2} \mathrm{bpy}$, and when pyridine was added to a solution of $\mathrm{Pd}\left(6,6^{\prime}-\mathrm{Me}_{2} \mathrm{bpy}\right)(\mathrm{OAc})_{2}$ at $-70^{\circ} \mathrm{C}$, an intermediate species was detected. Upon warming a solution of this species, it converted into a simple mixture of $\mathrm{Pd}\left(6,6^{\prime}-\mathrm{Me}_{2} \mathrm{bpy}\right)(\mathrm{OAc})_{2}$ and $\mathrm{Pd}(\mathrm{py})_{2}(\mathrm{OAc})_{2}$. NMR analysis of the intermediate showed evidence of dynamic exchange processes, even at $-90^{\circ} \mathrm{C}$, which prevented heteronuclear 2D NMR characterization similar to that used with $\mathrm{Pd}\left(\kappa^{1}-\mathrm{DAF}\right)(\mathrm{py})(\mathrm{OAc})_{2}$. Nevertheless, ${ }^{1} \mathrm{H}$ 1D TOCSY, EXSY and ROESY experiments (Figures S15 $\mp$ S16), in combination with integration of the $1 \mathrm{D}^{1} \mathrm{H}$ NMR spectrum, revealed a 6,6'- $\mathrm{Me}_{2}$ bpy ligand with two inequivalent rings (Figure 6). Through-space interactions between the 6,6'-Me 2 bpy, pyridine and two acetate ligands, and the integrations the respective peaks support a structure consisting of trans-Pd( $\left(\kappa^{1}-6,6^{\prime}-\mathrm{Me}_{2} \mathrm{bpy}\right)(\mathrm{py})\left(\kappa^{1}-\mathrm{OAc}\right)_{2}$ (Figure 6 ). To our knowledge, this direct observation of reversible $\kappa^{1}$ coordination for $6,6^{\prime}-\mathrm{Me}_{2}$ bpy is unprecedented. No evidence for dynamic exchange processes were evident in the pyridine titration studies of 2,9- $\mathrm{Me}_{2} \mathrm{phen} / \mathrm{Pd}(\mathrm{OAc})_{2}$ mixtures.

To summarize, the pyridine titration studies suggest the ligand binding strength of the different bidentate ligands follows the trend 4,4'- ${ }^{\mathrm{B}} \mathrm{Bu}_{2}$ bpy $>$ 2,9- $-\mathrm{Me}_{2}$ phen $>6,6-\mathrm{Me}_{2}$ bpy DAF. This trend inversely correlates with the relative yields and rates observed with these ligands in the aza-Wacker reaction (Table 1 and Figure 1). 4,4'- $-\mathrm{Bu}_{2}$ bpy and 2,9-Me 2 phen form static, strongly-bound $1: 1$ adducts with $\mathrm{Pd}(\mathrm{OAc})_{2}$, and both strongly inhibit the catalytic reaction. In contrast, 6,6'- $\mathrm{Me}_{2}$ bpy exhibits dynamic behavior in the presence of a monodentate donor ligand (pyridine), with transient formation of a $\kappa^{1}$-ligated bpy adduct, while DAF exhibits dynamic interconversion between $\kappa^{2}$ - and $\kappa^{1}$-coordination modes, even in the absence of a donor ligand (cf. Chart 1). The correlation between this bidentate ligand behavior and the respective catalytic activity supported by these ligands will be explored further below.

\section{Assessment of Ligand Effects on the Aza-Wacker Reaction Mechanism}

$\operatorname{Pd}(\mathrm{OAc})_{2} /$ py-ridine-catalyzed oxidative cyclization of 4-hexenyltosylamide has been the focus of previous mechanistic study and a simplified mechanism is depicted in Scheme 2. 
The reaction involves displacement of pyridine and an acetate ligand (as $\mathrm{AcOH}$ ) to afford an alkene/amidate-Pd ${ }^{\mathrm{II}}$ chelate, followed by insertion of the alkene into the $\mathrm{Pd}^{\mathrm{II}}-\mathrm{N}$ bond in a "cis-amidopalladation" reaction. Subsequent $\beta$-hydride elimination from the resulting alkyl$\mathrm{Pd}^{\mathrm{II}}$ species affords the vinyl-pyrrolidine product, and the $\mathrm{Pd}^{\mathrm{II}}$-hydride is then reoxidized by $\mathrm{O}_{2}$ in a multistep process via a $\mathrm{Pd}^{0}$ intermediate.

Amidopalladation of alkenes can proceed via a cis or trans pathway, depending on the identity of the catalyst or reaction conditions. ${ }^{24}$ Insight into the stereochemical course of the aza-Wacker reactions catalyzed by $\mathrm{Pd}(\mathrm{OAc})_{2} / 6,6^{\prime}-\mathrm{Me}_{2}$ bpy and $\mathrm{Pd}(\mathrm{OAc})_{2} / \mathrm{DAF}$ reaction was obtained by using the stereospecifically labeled cyclopentene- $d_{1}$ derivative I (Scheme 3 ). ${ }^{33}$ The bicylic product II, which arises from cis-amidopalladation of the alkene, was observed as the sole product of both reactions ( $72 \%$ and $98 \%$, respectively). This outcome is consistent with a mechanism similar to the $\mathrm{Pd}(\mathrm{OAc})_{2}$ /pyridine-catalyzed pathway in Scheme 2 .

Density functional theory (DFT) methods were used to explore the aza-Wacker reaction pathway with three different ligands, 2,9-Me $\mathrm{M}_{2}$ phen, 6,6'- $\mathrm{Me}_{2} \mathrm{bpy}$, and DAF. The calculations show that these ligands vary considerably in their binding strength to $\mathrm{Pd}(\mathrm{OAc})_{2}$, consistent with the experimental results describe above (cf. Table 2). The bidentate ligand complexes range from strongly favored for $2,9-\mathrm{Me}_{2}$ phen $(-7.1 \mathrm{kcal} / \mathrm{mol})$ to nearly isoergic for 6,6 '$\mathrm{Me}_{2}$ bpy $(-1.4 \mathrm{kcal} / \mathrm{mol})$ and DAF $(-1.8 \mathrm{kcal} / \mathrm{mol})$ (Scheme 4). For comparison, trans$\mathrm{Pd}(\mathrm{py})_{2}(\mathrm{OAc})_{2}$ has a calculated energy of $(-8.1 \mathrm{kcal} / \mathrm{mol})$, and coordination of the traditional bpy ligand $4,4^{\prime}{ }^{\mathrm{t}} \mathrm{Bu}_{2} \mathrm{bpy}$, which lack steric features or structural distortions that would disfavor binding, is strongly favored $\left(\Delta G^{\circ}=-15.8 \mathrm{kcal} / \mathrm{mol}\right)$.

(Z)-4-Hexenylmethanesulfonamide was the used as the substrate to assess aza-Wacker reaction pathways (Scheme 4). Formation of a $\mathrm{Pd}^{\mathrm{II}}$-amidate via proton-coupled displacement of an acetate ligand (i.e., with loss of $\mathrm{AcOH}$ ) is uphill by approx. $9 \mathrm{kcal} / \mathrm{mol}$ for the 2,9$\mathrm{Me}_{2}$ phen and 6,6'-Me 2 bpy complexes, but only by $2.3 \mathrm{kcal} / \mathrm{mol}$ for the DAF complex. This difference reflects steric effects of the methyl groups in 2,9- $\mathrm{Me}_{2}$ phen and 6,6'- $\mathrm{Me}_{2} \mathrm{bpy}$, which disfavor binding of the larger mesylamide group relative to acetate. Coordination of the alkene to afford a chelated alkene/amidate structure requires dissociation of another ligand from $\mathrm{Pd}^{\mathrm{II}}$. Loss of acetate to afford a cationic complex is energetically costly in a non-polar solvent, such as toluene. For example, formation of the DAF complex [Pd(DAF) (alkene/amidate) $]^{+} \mathrm{OAc}^{-}\left(\mathbf{D}^{\prime}\right)$ is calculated to have an energy of $29.0 \mathrm{kcal} / \mathrm{mol}$ (Figure 7). The experimental evidence for $\kappa^{2} / \kappa^{1}$ interconversion of DAF and 6,6'-Me 2 bpy (cf. Figures 5 and 6) prompted us to consider an alternative pathway involving dissociation of one of the pyridyl rings of the chelating ligand (i.e., $\mathbf{C} \rightarrow \mathbf{D}$ ). This step is especially accessible with DAF. The alkene/amidate-Pd ${ }^{\mathrm{II}}$ chelate lies at $7.2 \mathrm{kcal} / \mathrm{mol}$, which is only $9 \mathrm{kcal} / \mathrm{mol}$ higher in energy than the initial $\mathrm{Pd}(\mathrm{OAc})_{2} / \mathrm{DAF}$ complex. And, the subsequent transition state for alkene insertion into the $\mathrm{Pd}-\mathrm{N}$ bond (E) (i.e., cis-amidopalladation of the alkene) is at 18.6 $\mathrm{kcal} / \mathrm{mol}\left(\Delta G^{4}=20.4 \mathrm{kcal} / \mathrm{mol}\right.$ relative to $\left.\mathrm{Pd}(\mathrm{DAF})(\mathrm{OAc})_{2}\right)$. The analogous transition state with 6,6'- $\mathrm{Me}_{2}$ bpy is higher in energy $(25.8 \mathrm{kcal} / \mathrm{mol})$, but still quite accessible. The absolute energies of the 2,9- $\mathrm{Me}_{2}$ phen and 6,6'- $\mathrm{Me}_{2}$ bpy transition states differ by less than $2 \mathrm{kcal} / \mathrm{mol}$; however, $\mathrm{Pd}\left(2,9-\mathrm{Me}_{2}\right.$ phen $) \mathrm{OAc}_{2}$ has significant ground-state stability that results in a very high net activation energy $\left(\Delta G^{\dagger}=34.6 \mathrm{kcal} / \mathrm{mol}\right)$ and accounts for the inhibitory effect of 
this ligand. For comparison, the previously reported computational study of the $\mathrm{Pd}(\mathrm{py})_{2}(\mathrm{OAc})_{2}$-catalyzed reaction revealed a net activation energy for the reaction of 24.6 $\mathrm{kcal} / \mathrm{mol},{ }^{12 \mathrm{c}}$ which is higher than that of the DAF-based reaction, but lower than that of the reactions with 6,6'- $\mathrm{Me}_{2}$ bpy and 2,9- $\mathrm{Me}_{2}$ phen. The relative calculated activation-energies for the different ligands align with the relative experimental ligand-reactivity trends shown in Figure 1 and highlight the importance of both ground-state and transition-state ligand effects on the reaction.

Subsequent $\beta$-hydride elimination from the Pd-alkyl intermediate $\mathbf{F}$ is lower in energy than the amidopalladation step. The preferred pathway identified for this process features a concerted "reductive $\beta$-hydride elimination" step in which the $\beta$-hydrogen of alkyl ligand is transferred directly to the free oxygen of the carboxylate ligand, resulting in formation of a $\mathrm{Pd}^{0}$ product with a bound $\mathrm{AcOH}$ ligand $(\mathbf{H})$, rather than a $\mathrm{Pd}^{\mathrm{II}}$-hydride species. A similar pathway was identified previously for a Pd-catalyzed alcohol oxidation reaction. ${ }^{34}$ Loss of the $\mathrm{AcOH}$ ligand from this complex is energetically favorable, and subsequent oxidation of the resultsing $\operatorname{Pd}(\mathrm{N} \sim \mathrm{N})$ (alkene) complex is expected to be very facile, on the basis of prior studies of this reaction. ${ }^{5 \mathrm{a}, \mathrm{e}, 35}$

\section{Conclusions and Implications for Aerobic Oxidation Catalysis}

The results presented above add another Pd-catalyzed aerobic oxidation method to the growing number of reactions that benefit from the use of DAF as an ancillary ligand. In the present case, DAF is the only bidentate bpy/phen-type ligand among numerous examples that supports efficient catalytic turnover at room temperature. Perhaps more importantly, the results described here provide some of the first clear insights into the unique ability of DAF to promote these reactions.

The unusual coordination properties of DAF, evident in Chart $1^{22}$ and elsewhere, ${ }^{23}$ reflect the structural differences of DAF relative traditional bpy- and phen-type ligands that make it a non-ideal chelating ligand (cf. Figure 3). Coordination of DAF to $\mathrm{Pd}^{\mathrm{II}}$ as a bidentate ligand requires a distortion of the DAF ligand, and the resulting strain raises the ground-state energy of the catalyst. This strain contributes to the low-energy interconversion between $\kappa^{2} / \kappa^{1}$ ligand-coordination modes, which then facilitates binding of the alkene substrate to $\mathrm{Pd}^{\mathrm{II}}$ and lowers the transition-state energy of the rate-limiting cis-amidopalladation step. The reaction pathway in Scheme 4 highlights the synergistic participation of the basic X-type ligand (acetate), which undergoes proton-coupled exchange with the $\mathrm{N}-\mathrm{H}$ group of the amide substrate (i.e., $\mathrm{N}-\mathrm{H}$ activation), and a neutral L-type ligand (one of the pyridyl rings of DAF) that is readily displaced to enable activation of the neutral alkene.

There are aspects of the "ligand acceleration" effect that remain unclear, but the salient point is that DAF does not bind as strongly to $\mathrm{Pd}(\mathrm{OAc})_{2}$ as does pyridine or traditional bidentate ligands. This point is highlighted in Table 2 and appears again in the computational studies (Scheme 4). More-stable catalyst ground states contribute to higher net activation barriers in the catalytic reaction. 
Similar ligand effects are expected to play important roles in other Pd-catalyzed aerobic oxidations, which typically require coordination of both X- and L-type substrate fragments at the $\mathrm{Pd}{ }^{\mathrm{II}}$ center. For example, $\alpha, \beta$-dehydrogenation of ketones, ${ }^{19}$ oxidative Heck (i.e., aryl$\mathrm{C}-\mathrm{H} /$ alkene) coupling ${ }^{20}$ and allylic $\mathrm{C}-\mathrm{H}$ oxidation reactions ${ }^{17,21}$ have been promoted by DAF as an ancillary ligand. Each of these reactions resemble the aza-Wacker reaction in that they feature steps that require simultaneous access to L- and X-type ligand sites by the substrate(s) and/or involve carboxylate-mediated activation of a substrate that is coordinated to $\mathrm{Pd}^{\mathrm{II}}$ as a neutral donor ligand (Figure 8). Each of these reactions is expected to benefit from the strain-induced hemilability of the DAF ligand, which provide low-energy access to an open L-type coordinate site at $\mathrm{Pd}^{\mathrm{II}}$.

Collectively, the insight gained from this study illuminate features of DAF that make it especially effective in many Pd-catalyzed aerobic oxidation reactions. Current efforts are being directed toward the intentional design and testing of new ligands with similar features that could prove to be even more effective than DAF.

\section{Supplementary Material}

Refer to Web version on PubMed Central for supplementary material.

\section{Acknowledgments}

We thank Dr. Charlie Fry for NMR assistance as well as Dr. Ilia Guzei and Brian Dolinar for assistance with X-ray crystallographic analysis of $\mathrm{Pd}\left(\kappa^{1}-\mathrm{DAF}\right)(\mathrm{py})(\mathrm{OAc}) 2$ and $\mathrm{Pd}\left(6,6^{\prime}-\mathrm{Me} 2 \mathrm{bpy}\right)(\mathrm{OAc}) 2$. We are grateful for financial support from the NIH (R01 GM67173). Computational resources are supported in part by the NSF (CHE-0840494). NMR instrumentation was partially funded by the NIH S10 RR13866-01 and NIH S10 OD012245.

\section{References}

1.

For general reviews of this field, see: Stahl SS. Angew Chem Int Ed. 2004; 43:3400-3420.Gligorich

KM, Sigman MS. Chem Commun. 2009; 26:3854-3867.

2.

For more-focused reviews/perspectives, see: Sheldon RA, Arends IWCE, ten Brink G-J, Dijksman A.

Acc Chem Res. 2002; 35:774-781. [PubMed: 12234207] Toyota M, Ihara M. Synlett. 2002;

8:1211-1222.Nishimura T, Uemura S. Synlett. 2004:201-216.Stoltz BM. Chem Lett. 2004; 33:362-

367.Sigman MS, Jensen DR. Acc Chem Res. 2006; 39:221-229. [PubMed: 16548511] Kotov V,

Scarborough CC, Stahl SS. Inorg Chem. 2007; 46:1910-1923. [PubMed: 17348722] Campbell AN,

Stahl SS. Acc Chem Res. 2012; 45:851-863. [PubMed: 22263575]

3.

For studies probing ligand effects on catalyst stability, see: ten Brink G-J, Arends IWCE, Hoogenraad

M, Verspui G, Sheldon RA. Adv Synth Catal. 2003; 345:497-505.ten Brink G-J, Arends IWCE,

Hoogenraad M, Verspui G, Sheldon RA. Adv Synth Catal. 2003; 345:497-505.Steinhoff BA, Fix

SR, Stahl SS. J Am Chem Soc. 2002; 124:766-767. [PubMed: 11817948] Steinhoff BA, Stahl SS. J

Am Chem Soc. 2006; 128:4348-4355. [PubMed: 16569011]

4. 
For reviews of Pd/O 2 reactivity, see: Muzart J. Chem Asian J. 2006; 1:508-515. [PubMed: 17441088]

Popp B, Stahl SS. Top Organomet Chem. 2007; 22:149-189.Scheuermann ML, Goldberg KI. Chem Eur J. 2014; 20:14556-14568. [PubMed: 25303084]

5.

For investigation of $\mathrm{Pd}^{0}$ oxidation by $\mathrm{O}_{2}$ in relation to aerobic oxidation catalysis, see: Stahl SS,

Thorman JL, Nelson RC, Kozee MA. J Am Chem Soc. 2001; 123:7188-7189. [PubMed: 11459511]

Landis CR, Morales CM, Stahl SS. J Am Chem Soc. 2004; 126:16302-16303. [PubMed:

15600314] Konnick MM, Guzei IA, Stahl SS. J Am Chem Soc. 2004; 126:10212-10213. [PubMed:

15315411] Konnick MM, Stahl SS. J Am Chem Soc. 2008; 130:5753-5762. [PubMed: 18393426]

Popp BV, Stahl SS. Chem Eur J. 2009; 15:2915-2922. [PubMed: 19191243] Ingram AJ, Solis-

Ibarra D, Zare RN, Waymouth RM. Angew Chem Int Ed. 2014; 53:5648-5652.Ingram AJ, Walker

KL, Zare RN, Waymouth RM. J Am Chem Soc. 2015; 137:13632-13646. [PubMed: 26444100]

6.

For leading references, see reference $2 \mathrm{e}$ and following leading references: Ferreira EM, Stoltz BM. J

Am Chem Soc. 2001; 123:7725-7726. [PubMed: 11481006] Jensen DR, Pugsley JS, Sigman MS. J

Am Chem Soc. 2001; 123:7475-7476. [PubMed: 11472200] Ebner DC, Bagdanoff JT, Ferreira EM, McFadden RM, Caspi DD, Trend RM, Stoltz BM. Chem Eur J. 2009; 15:12978-12992. [PubMed: 19904777]

7. (a) Andappan MMS, Nilsson P, von Schenck H, Larhed M. J Org Chem. 2004; 69:5212-5218. [PubMed: 15287763] (b) Zheng C, Wang D, Stahl SS. J Am Chem Soc. 2012; 134:16496-16499. [PubMed: 22998540] (c) Zheng C, Stahl SS. Chem Commun. 2015; 51:12771-12774.

8. (a) Yoo KS, Park CP, Yoon CH, Sakaguchi S, O'Neil J, Jung KW. Org Lett. 2007; 9:3933-3935. [PubMed: 17760452] (b) Sakaguchi S, Yoo KS, O'Neill J, Lee JH, Stewart T, Jung KW. Angew Chem Int Ed. 2008; 47:9326-9329.(c) Yoo KS, O’Neill J, Sakaguchi S, Giles R, Lee JH, Jung KW. J Org Chem. 2010; 75:95-101. [PubMed: 19954185] (d) Mei TS, Werner EW, Burckle AJ, Sigman MS. J Am Chem Soc. 2013; 135:6830-6833. [PubMed: 23607624] (e) Mei TS, Patel HH, Sigman MS. Nature. 2014; 508:340-344. [PubMed: 24717439] (f) Zhang C, Santiago CB, Crawford JM, Sigman MS. J Am Chem Soc. 2015; 137:15668-15671. [PubMed: 26624236]

9.

An important ligand class complementary to the ligands described here are amino acids, highlighted by the work of J. Q. Yu and coworkers. For leading references, see: Shi BF, Maugel N, Zhang YH, Yu JQ. Angew Chem Int Ed. 2008; 47:4882-4886.Wang DH, Engle KM, Shi BF, Yu JQ. Science. 2010; 327:315-319. [PubMed: 19965380] Shi BF, Zhang YH, Lam JK, Wang DH, Yu JQ. J Am Chem Soc. 2010; 132:460-461. [PubMed: 20017549] Engle KM, Wang DH, Yu JQ. J Am Chem Soc. 2010; 132:14137-14151. [PubMed: 20853838] Engle KM, Thuy-Boun PS, Dang M, Yu JQ. J Am Chem Soc. 2011; 133:18183-18193. [PubMed: 21913636] Baxter RD, Sale D, Engle KM, Yu JQ, Blackmond DG. J Am Chem Soc. 2012; 134:4600-4606. [PubMed: 22324814]

10. (a) Nishimura T, Onoue T, Ohe K, Uemura S. Tetrahedron Lett. 1998; 39:6011-6014.(b) Nishimura T, Onoue T, Ohe K, Uemura S. J Org Chem. 1999; 64:6750-6755. [PubMed: 11674682]

11. Fix SR, Brice JL, Stahl SS. Angew Chem Int Ed. 2002; 41:164-166.

12. (a) Steinhoff BA, Stahl SS. Org Lett. 2002; 4:4179-4181. [PubMed: 12423116] (b) Steinhoff BA, Guzei IA, Stahl SS. J Am Chem Soc. 2004; 126:11268-11278. [PubMed: 15355108] (c) Ye XA, Liu GS, Popp BV, Stahl SS. J Org Chem. 2011; 76:1031-1044. [PubMed: 21250706] 13.

For insights into pyridine ligand effects on Pd-catalyzed C-H oxidation reactions, see the following:

Zhang YH, Shi BF, Yu JQ. J Am Chem Soc. 2009; 131:5072-5074. [PubMed: 19296661] Emmert MH, Cook AK, Xie YJ, Sanford M. Angew Chem Int Ed. 2011; 50:9409-9412.Gary JB, Cook 
AK, Sanford MS. ACS Catal. 2013; 3:700-703.Kubota A, Emmert MH, Sanford MS. Org Lett. 2012; 14:1760-1763. [PubMed: 22409653] Cook AK, Sanford MS. J Am Chem Soc. 2015;

137:3109-3118. [PubMed: 25706227]

14. Fix SR, Stahl SS. unpublished results.

15.

For representative examples, see the following references. In some cases, bpy and phen inhibit catalytic turnover, while other bidentate ligands show some utility. (a) ref. 7a. Andappan MMS, Nilsson P, Larhed M. Chem Commun. 2004; 2:218-219.Izawa Y, Stahl SS. Adv Synth Catal. 2010; 352:3223-3229. [PubMed: 21399704] Ying CH, Yan SB, Duan WL. Org Lett. 2014; 16:500-503. [PubMed: 24378012]

16.

Bidentate ligands have been used successfully in Pd-catalyzed aerobic oxidation reactions, as documented in the following references. These examples invariably feature a polar/coordinating solvent (e.g., water, DMSO, dimethyl acetamide, $\mathrm{DMF}, \mathrm{CH}_{3} \mathrm{CN}$ ) or weakly coordinating anionic ligands (e.g., $\mathrm{CF}_{3} \mathrm{CO}_{2}^{-}, \mathrm{OTf}^{-}$). The effectiveness of bidentate ligands in these reactions probably reflects the enhanced kinetic lability of anionic ligands under these conditions. See references $3 \mathrm{a}, \mathrm{b}$, 8, ten Brink G-J, Arends WCEI, Papadogianakis G, Sheldon AR. Chem Commun. 1998; 21:23592360.Bianchi D, Bortolo R, D'Aloisio R, Ricci M. Angew Chem Int Ed. 1999; 38:706-708.ten Brink G-J, Arends IWCE, Sheldon RA. Science. 2000; 287:1636-1639. [PubMed: 10698735] Conley NR, Labios LA, Pearson DM, McCrory CCL, Waymouth RM. Organometallics. 2007; 26:5447-5453.He W, Yip KT, Zhu NY, Yang D. Org Lett. 2009; 11:5626-5628. [PubMed: 19905004] Jensen KH, Pathak TP, Zhang Y, Sigman MS. J Am Chem Soc. 2009; 131:1707417075. [PubMed: 19902942] McDonald RI, White PB, Weinstein AB, Tam CP, Stahl SS. Org Lett. 2011; 13:2830-2833. [PubMed: 21534607] Chung K, Banik SM, De Crisci AG, Pearson DM, Blake TR, Olsson JV, Ingram AJ, Zare RN, Waymouth RM. J Am Chem Soc. 2013; 135:75937602. [PubMed: 23659308] De Crisci AG, Chung K, Oliver AG, Solis-Ibarra D, Waymouth RM. Organometallics. 2013; 32:2257-2266.

17. Campbell AN, White PB, Guzei IA, Stahl SS. J Am Chem Soc. 2010; 132:15116-15119. [PubMed: 20929224]

18. (a) Campbell AN, Meyer EB, Stahl SS. Chem Commun. 2011; 47:10257-10259.(b) Xiao B, Gong TJ, Liu ZJ, Liu JH, Luo DF, Xu J, Liu L. J Am Chem Soc. 2011; 133:9250-9253. [PubMed: 21609019]

19. (a) Gao WM, He ZQ, Qian Y, Zhao J, Huang Y. Chem Sci. 2012; 3:883-886.(b) Diao T, Wadzinski TJ, Stahl SS. Chem Sci. 2012; 3:887-891. [PubMed: 22690316] (c) Buter J, Moezelaar R, Minnaard AJ. Org Biomol Chem. 2014; 12:5883-5890. [PubMed: 24984187]

20. (a) Piotrowicz M, Zakrzewski J. Organometallics. 2013; 32:5709-5712.(b) Piotrowicz M, Zakrzewski J, Métivier R, Brosseau A, Makal A, WoŸniak K. J Org Chem. 2015; 80:2573-2581. [PubMed: 25642784] (c) Vasseur A, Laugel C, Harakat D, Muzart J, Le Bras J. Eur J Org Chem. 2015; 2015:944-948.

21. (a) Sharma A, Hartwig JF. J Am Chem Soc. 2013; 135:17983-17989. [PubMed: 24156776] (b) Malik HA, Taylor BLH, Kerrigan JR, Grob JE, Houk KN, Du Bois J, Hamann LG, Patterson AW. Chem Sci. 2014; 5:2352-2361. [PubMed: 25685311]

22. White PB, Jaworski JN, Fry CG, Dolinar BS, Guzei IA, Stahl SS. J Am Chem Soc. 2016; 138 ASAP. 10.1021/jacs.6b01188

23.

For a review of DAF coordination chemistry, see: Annibale See VT, Song D. Dalton Trans. 2016; 45:32-49. [PubMed: 26621438]

24. McDonald RI, Liu GS, Stahl SS. Chem Rev. 2011; 111:2981-3019. [PubMed: 21428440] 
25.

For additional reviews, see: Zeni G, Larock RC. Chem Rev. 2004; 104:2285-2309. [PubMed: 15137792] Beccalli EM, Broggini G, Martinelli M, Sottocornola S. Chem Rev. 2007; 107:53185365. [PubMed: 17973536] Minatti A, Muñiz K. Chem Soc Rev. 2007; 36:1142-1152. [PubMed: $17576481]$

26.

See reference $16 \mathrm{~g}$ and also the following: Tamaru Y, Tanigawa H, Itoh S, Kimura M, Tanaka S, Fugami K, Sekiyama T, Yoshida Z-i. Tetrahedron Lett. 1992; 33:631-634.Vanbenthem R, Hiemstra H, Longarela GR, Speckamp WN. Tetrahedron Lett. 1994; 35:9281-9284.Larock RC, Hightower TR, Hasvold LA, Peterson KP. J Org Chem. 1996; 61:3584-3585. [PubMed: 11667199] Fix SR, Brice JL, Stahl SS. Angew Chem Int Ed. 2002; 41:164-166.Rogers MM, Wendlandt JE, Guzei IA, Stahl SS. Org Lett. 2006; 8:2257-2260. [PubMed: 16706500] Scarborough CC, Stahl SS. Org Lett. 2006; 8:3251-3254. [PubMed: 16836378] Lu Z, Stahl SS. Org Lett. 2012; 14:1234-1237. [PubMed: 22356620]

27.

See reference 12c and the following: Liu G, Stahl SS. J Am Chem Soc. 2007; 129:6328-6335.

[PubMed: 17439217] Ye X, White PB, Stahl SS. J Org Chem. 2013; 78:2083-2090. [PubMed: 23157332]

28.

In our previous study, focused on the coordination chemistry of DAF with Pd-carboxylate complexes, we investigated complexes bearing $\mathrm{CF}_{3} \mathrm{CO}_{2}-(\mathrm{TFA})$ and $t \mathrm{BuCO}_{2}-(\mathrm{OPiv})$ as anionic ligands. Unfortunately, Pd(TFA) 2 and its DAF complexes are insoluble under the present catalytic conditions, unless TFAH is added or a very polar solvents are used (the latter approach, however, leads to dissociation of DAF). DAF/Pd(OPiv $)_{2}$ in the catalytic reaction was attempted; however, the reaction is very slow. Consequently, systematic studies of the TFA- and OPiv-based catalyst systems were not performed.

29.

See Figure S4 in the Supporting Information for a comparison of DAF and $\mathrm{Me}_{2} \mathrm{DAF}$ in catalytic reactions performed at room temperature. The reaction proceeds much better with DAF, and therefore DAF was used in the subsequent systematic studies.

30. (a) Milani B, Alessio E, Mestroni G, Sommazzi A, Garbassi F, Zangrando E, Bresciani-Pahor N, Randaccio L. J Chem Soc, Dalton Trans. 1994; 13:1903-1911.(b) Moulin S, Pellerin O, Toupet L, Paul F. C R Chim. 2014; 17:521-525.

31.

Note: We had hoped to perform all of the studies (catalytic and mechanistic) in a uniform solvent (toluene); however, use of toluene as a solvent in our fundamental studies resulted in precipitation of the ligated $\mathrm{DAF} / \mathrm{Pd}(\mathrm{OAc})_{2}$ complexes. It was necessary to use a more polar solvent in these stoichiometric reactions. Control reactions were performed to confirm that $\mathrm{CDCl}_{3}$ is a competent solvent for the catalytic reaction. The reactions are successful in $\mathrm{CDCl}_{3}$; however, this solvent results in more Pd decomposition (Pd black).

32.

A similar structure of $\mathrm{Pd}\left(\kappa^{1}-\mathrm{Me}_{2} \mathrm{DAF}\right)($ pyridine $)(\mathrm{OAc})_{2}$ was also characterized. See supporting information for details. For $\mathrm{Pd}^{0}$ complexes bearing $\mathrm{K}^{1}$-DAF ligands, see: Klein RA, Witte P, van Belzen R, Fraanje J, Goubitz K, Numan M, Schenk H, Ernsting JM, Elsevier CJ. Eur J Inorg Chem. 1998; 3:319-330.

33. 
For previous applications of this substrate probe, see references $12 \mathrm{c}, 27 \mathrm{a}, \mathrm{b}$, and the following: Weinstein AB, Stahl SS. Angew Chem Int Ed. 2012; 51:11505-11509.

34. Nielsen RJ, Goddard WA. J Am Chem Soc. 2006; 128:9651-9660. [PubMed: 16866517]

35. Popp BV, Thorman JL, Stahl SS. J Mol Catal, A: Chem. 2006; 251:2-7. 


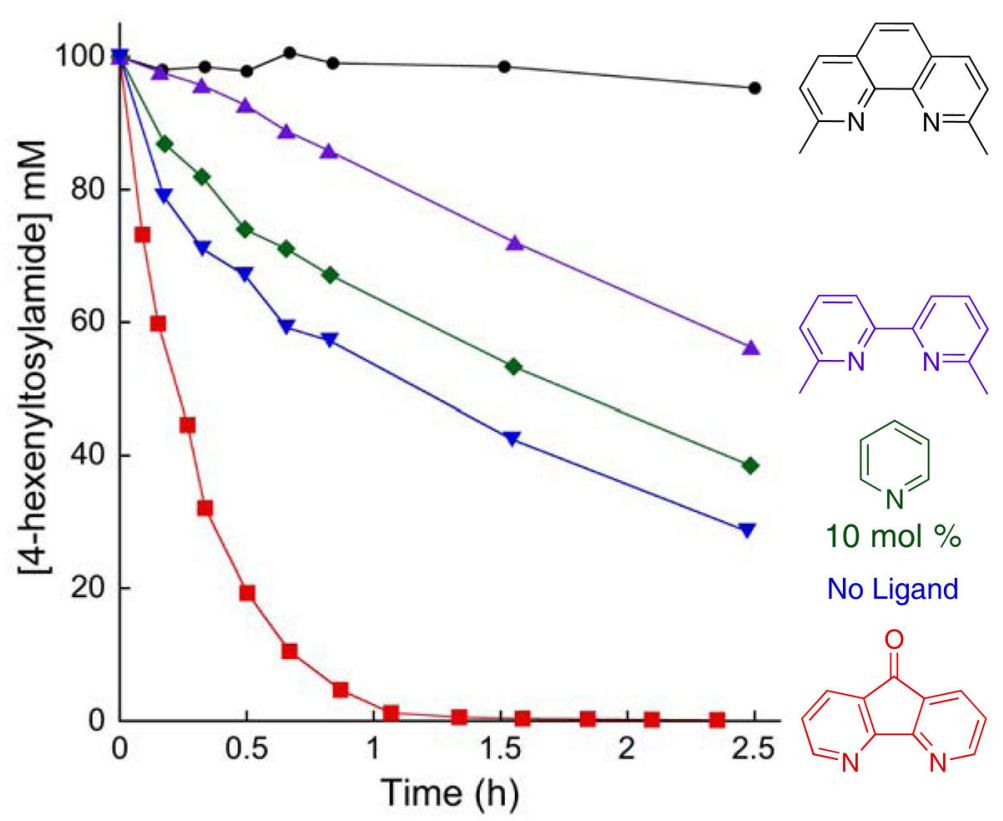

Figure 1.

Kinetic time courses of the oxidative cyclization of 1 . Conditions: 5 mol \% $\mathrm{Pd}(\mathrm{OAc})_{2}(3.4$ $\mathrm{mg}, 15 \mu$ moles), ligand (2,9-Me 2 phen, 6,6'- $\mathrm{Me}_{2}$ bpy, DAF = 5 mol $\% 15 \mu$ moles; pyridine: $10 \mathrm{~mol} \% 30$ umoles), 1 ( $76 \mathrm{mg}, 300 \mu$ moles, $0.1 \mathrm{M}), 50{ }^{\circ} \mathrm{C}, 1$ atm $\mathrm{O}_{2}$, toluene $(3 \mathrm{~mL})$, int. std. $=1,3,5$-trimethoxybenzene. The reaction was followed for 2.5 hours for with data collected every $5 \mathrm{~min}$ for DAF, and the other ligands were followed with data collected every $10 \mathrm{~min}$ for the first $50 \mathrm{~min}$ and every hour for two more hours. 
A. 10
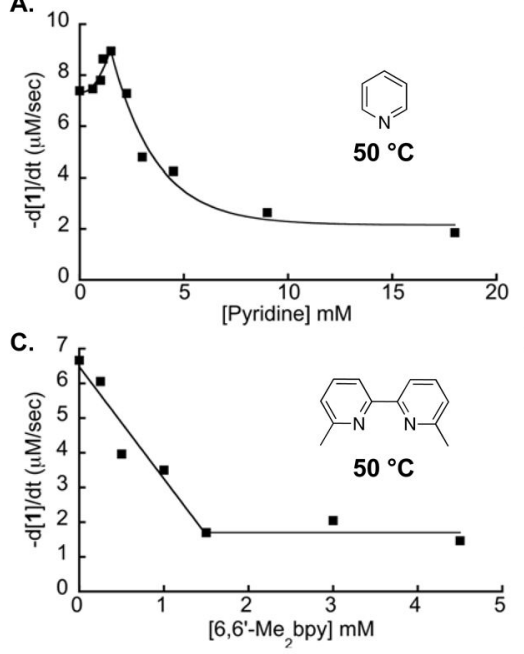

B.

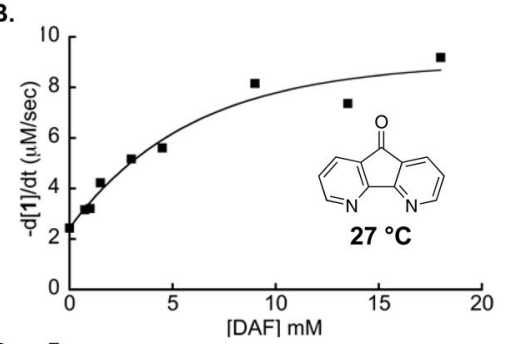

D.

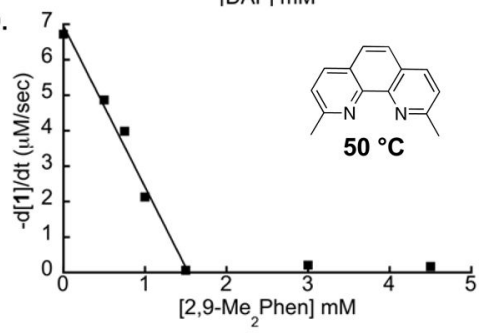

Figure 2.

Kinetic dependence of the initial rate of the oxidation of $\mathbf{1}$ on [ligand]. Conditions were as followed: $[$ Substrate $]=0.1 \mathrm{M},\left[\mathrm{Pd}(\mathrm{OAc})_{2}\right]=1.5 \mathrm{mM}, 3 \mathrm{~mL}, p \mathrm{O}_{2}=730$ torr, toluene $(3 \mathrm{~mL})$. (A) $[\mathrm{DAF}]=0-18 \mathrm{mM}, 27^{\circ} \mathrm{C}$. (B) $[$ Pyridine $]=0-18 \mathrm{mM} 50{ }^{\circ} \mathrm{C}$. (C) $\left[6,6^{\prime}-\mathrm{Me}_{2} \mathrm{bpy}\right]=0-4.5$ $\mathrm{mM}, 50{ }^{\circ} \mathrm{C}$. (D) $\left[2,9-\mathrm{Me}_{2} \mathrm{phen}\right]=0-4.5 \mathrm{mM}, 50{ }^{\circ} \mathrm{C}$. 

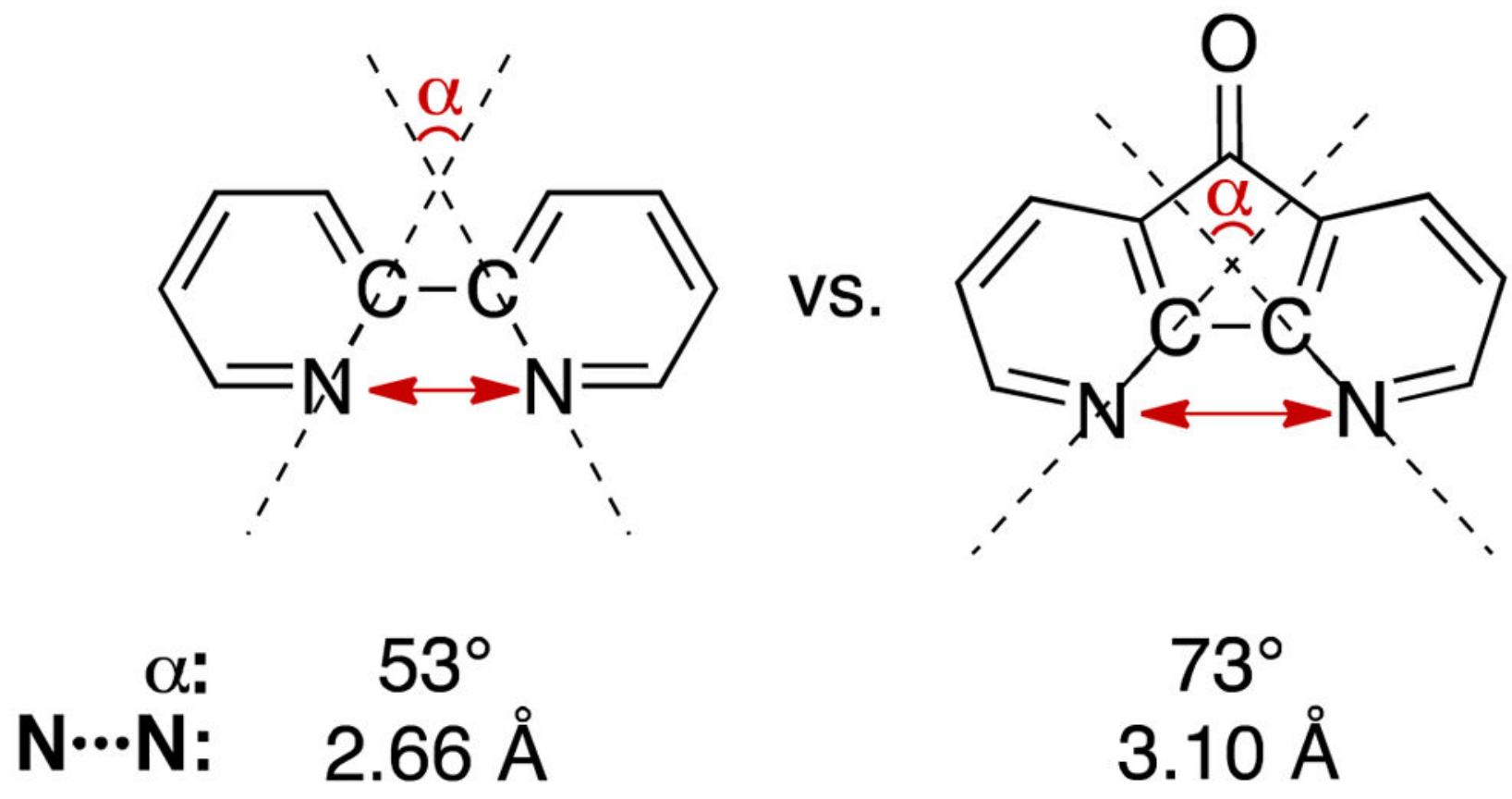

Figure 3.

Comparison of uncoordinated bpy and DAF ligands, highlighting the structural distortion of DAF. 


\section{A. Crystal Structure of $\mathrm{Pd}\left(6,6^{\prime}-\mathrm{Me}_{2} \mathrm{bpy}\right)(\mathrm{OAc})_{2}$.}

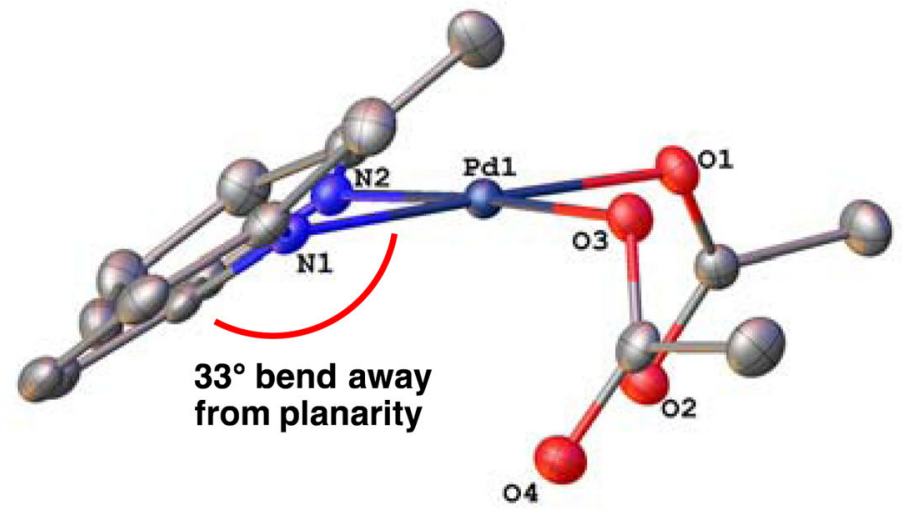

B. Steric Interactions Formed Upon Chelation to $\mathrm{Pd}(\mathrm{OAc})_{2}$

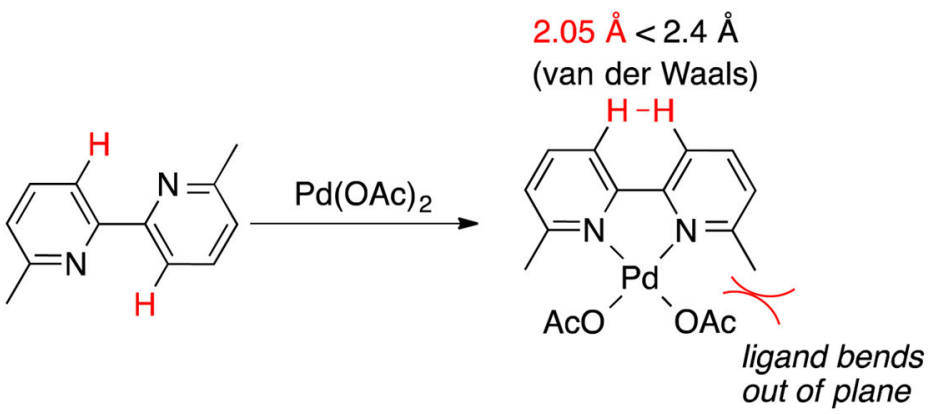

Figure 4.

X-ray crystal structure of $\mathrm{Pd}\left(6,6^{\prime}-\mathrm{Me}_{2} \mathrm{bpy}\right)(\mathrm{OAc})_{2}$ depicting the steric effects of the methyl groups that causes bending of the 6,6'- $\mathrm{Me}_{2}$ bpy ligand out of the $\mathrm{Pd}^{\mathrm{II}}$ square plane by $27^{\circ}$. (A; the molecular representation of the crystal structure is drawn with $50 \%$ thermal ellipsoids and the hydrogen atoms are omitted for clarity). Illustration of the steric clash between the 3 and 3 ' hydrogen atoms of the 6,6'- $\mathrm{Me}_{2}$ bpy ligand (B). 
A. Species observed from mixtures of $\mathrm{Pd}(\mathrm{OAc})_{2}, \mathrm{DAF}$ and pyridine.

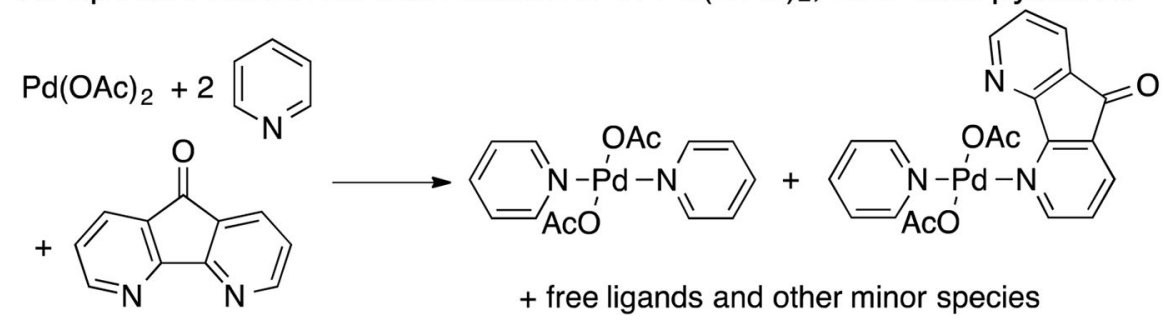

B. X-ray crystal structure of $\mathrm{Pd}\left(\kappa^{1}-\mathrm{DAF}\right)(\mathrm{py})(\mathrm{OAc})_{2}$.

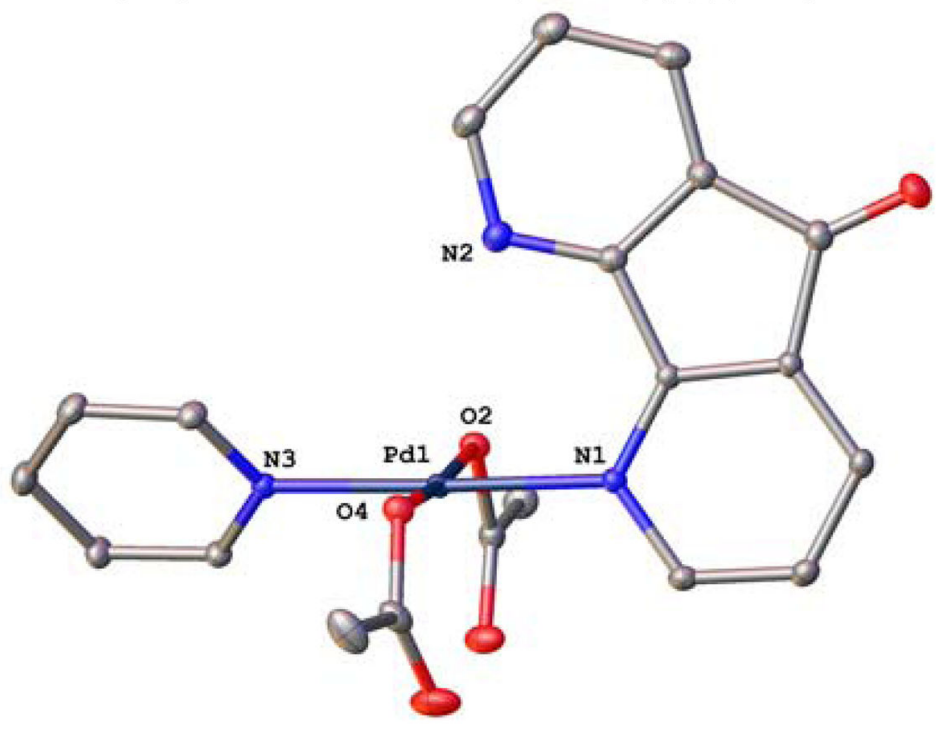

Figure 5.

Observation of a mixed DAF/pyridine intermediate, $\mathbf{8}$, characterized by NMR spectroscopy (A) and X-ray crystallography (B). Molecular diagram of the crystal is drawn with 50\% probability ellipsoids and all $\mathrm{H}$ atoms are omitted for clarity. 


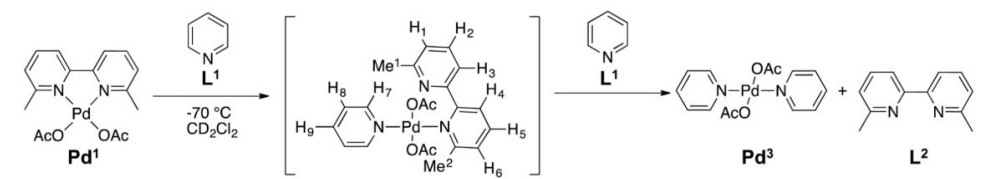

$\mathbf{P d}^{2}$ "transient
"peak assignment based on 10 TOCSY,
ROESY

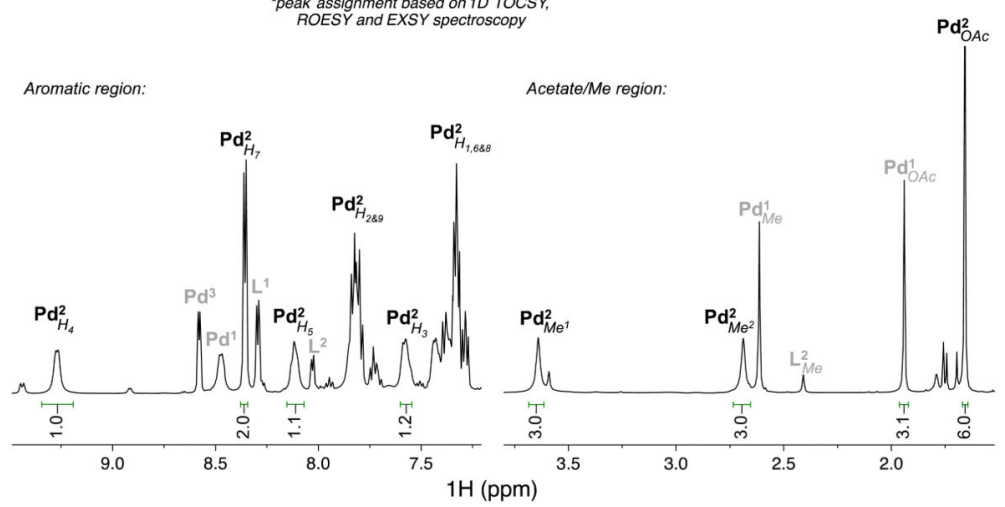

Figure 6.

Observation of a mixed 6,6'-Me 2 bpy/pyridine intermediate, $\beta$, characterized by NMR spectroscopy at $-70{ }^{\circ} \mathrm{C}(\mathrm{ns}=8, \mathrm{ds}=2, \mathrm{~d} 1=20 \mathrm{~s})$. The integrations of the aromatic and aliphatic protons are consistent with trans- $\mathrm{Pd}\left(\kappa^{1}-6,6^{\prime}-\mathrm{Me}_{2} \mathrm{bpy}\right)(\mathrm{py})(\mathrm{OAc})_{2}$. Correlations within and between ligands were made with 1D TOCSY and ROESY experiments at $-70{ }^{\circ} \mathrm{C}$ (See Supporting Information, Figures S15干S16). 


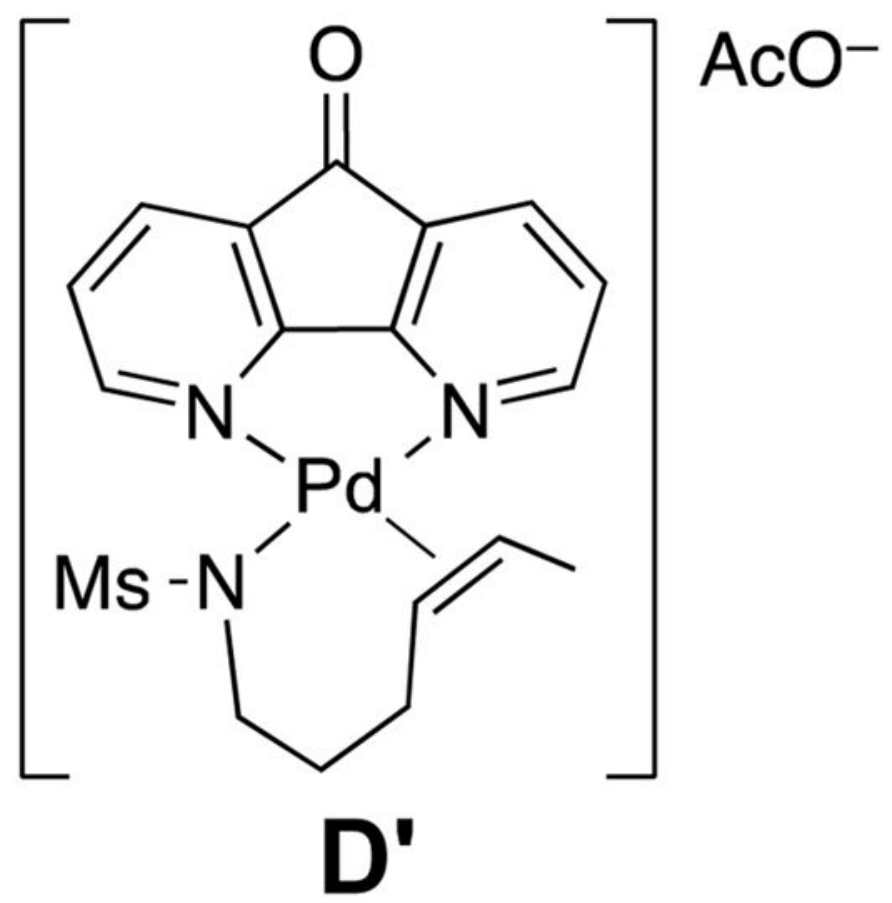

\section{$\Delta G_{\text {calc }}^{\circ}=29.0 \mathrm{kcal} / \mathrm{mol}$}

Figure 7.

DAF complex $[\mathrm{Pd}(\mathrm{DAF})(\text { alkene/amidate })]^{+} \mathrm{OAc}^{-}\left(\mathbf{D}^{\prime}\right)$.

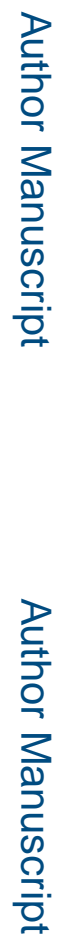




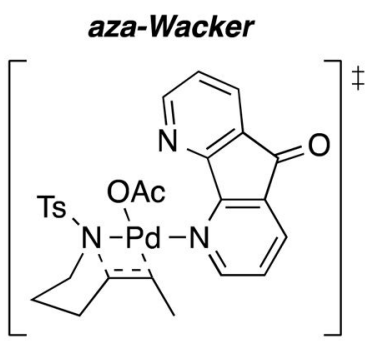

$\alpha, \beta$-dehydrogenation
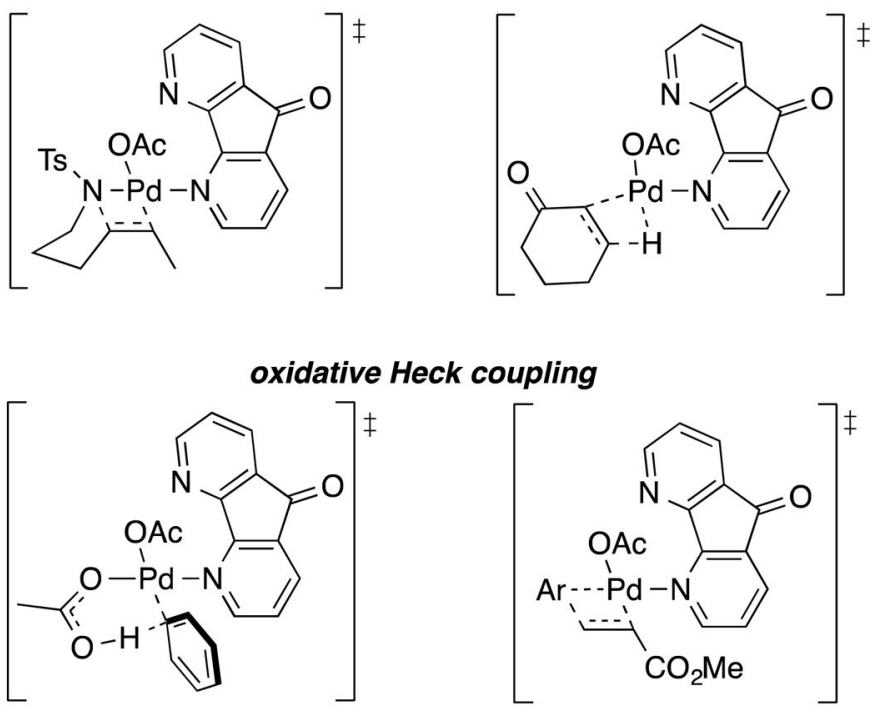

allylic $\mathrm{C}-\mathrm{H}$ activation

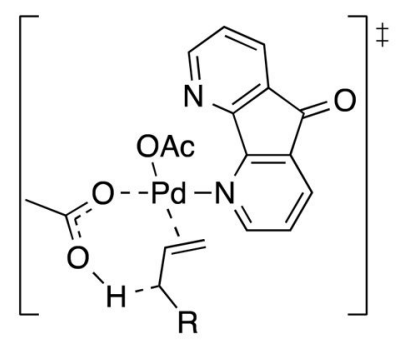

Figure 8.

Representative transition-state structures in Pd-catalyzed aerobic oxidation reactions that feature substrate coordination to $\mathrm{Pd}^{\mathrm{II}}$ in L- and X-type ligand sites and/or involvement of carboxylate-mediated activation of a substrate that is coordinated to $\mathrm{Pd}^{\mathrm{II}}$ as a neutral donor ligand. 


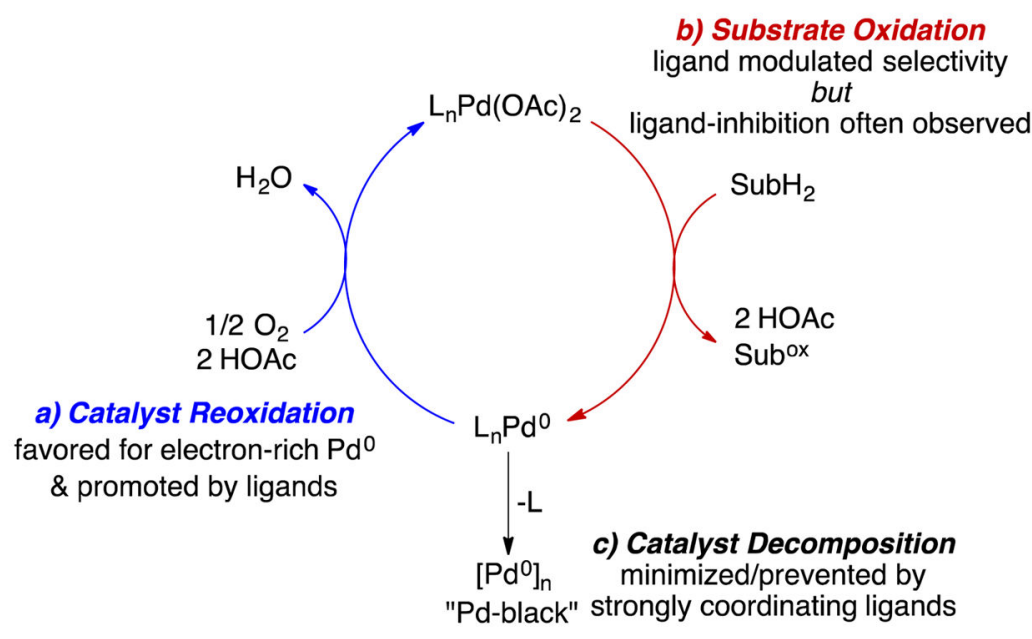

Scheme 1.

Simplified Mechanism and Overview of Ligand Effects in Pd-Catalyzed Aerobic Oxidation Reactions. 


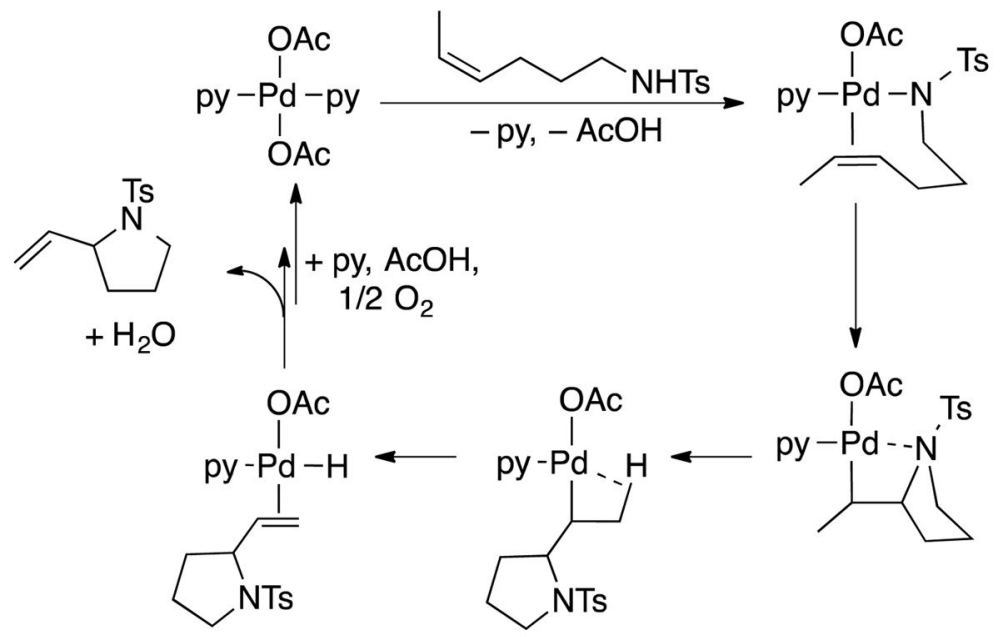

Scheme 2.

Mechanism of $\mathrm{Pd}(\mathrm{OAc})_{2} /$ Pyridine-Catalyzed Aza-Wacker Cyclization. 

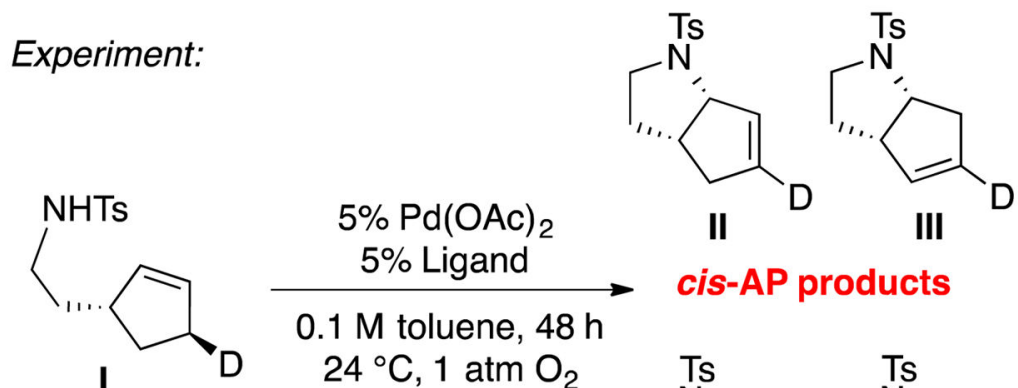

cis-AP products
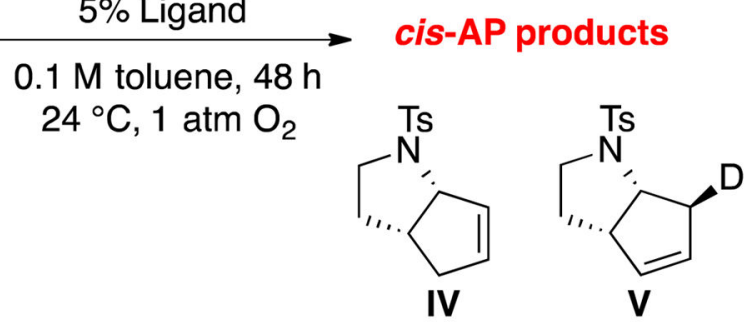

trans-AP products

Results:<smiles>Cc1cccc(-c2cccc(C)n2)n1</smiles>

$72 \%$ yield of II cis-AP Only

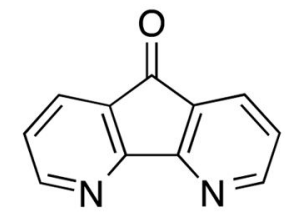

$98 \%$ yield of II cis-AP Only

Scheme 3.

Assessment of cis- vs. trans-Amidopalladation (AP) Pathway with $\mathrm{Pd}(\mathrm{OAc})_{2} / 6,6^{\prime}-\mathrm{Me}_{2}$ bpy and $\mathrm{Pd}(\mathrm{OAc})_{2} / \mathrm{DAF}$ Catalyst Systems. 


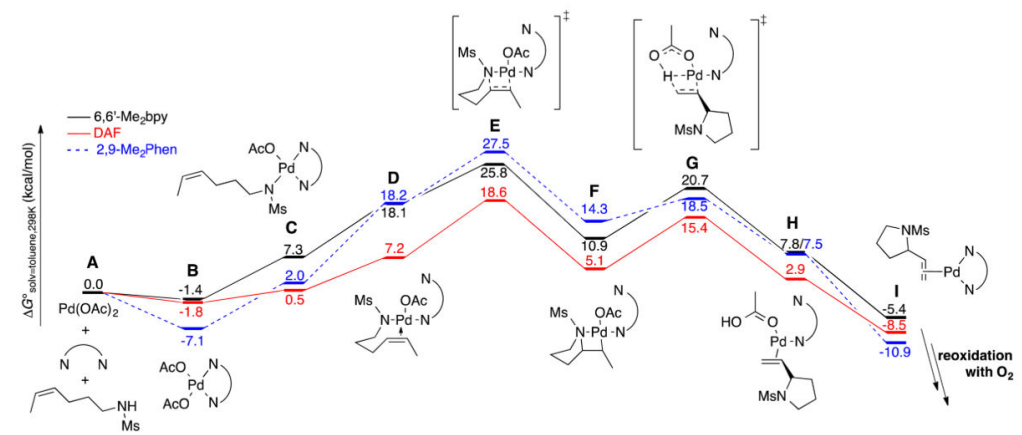

Scheme 4.

Aza-Wacker Reaction Pathway and Energetics for DAF, 6,6'- $\mathrm{Me}_{2}$ bpy and 2,9-Me 2 phen 

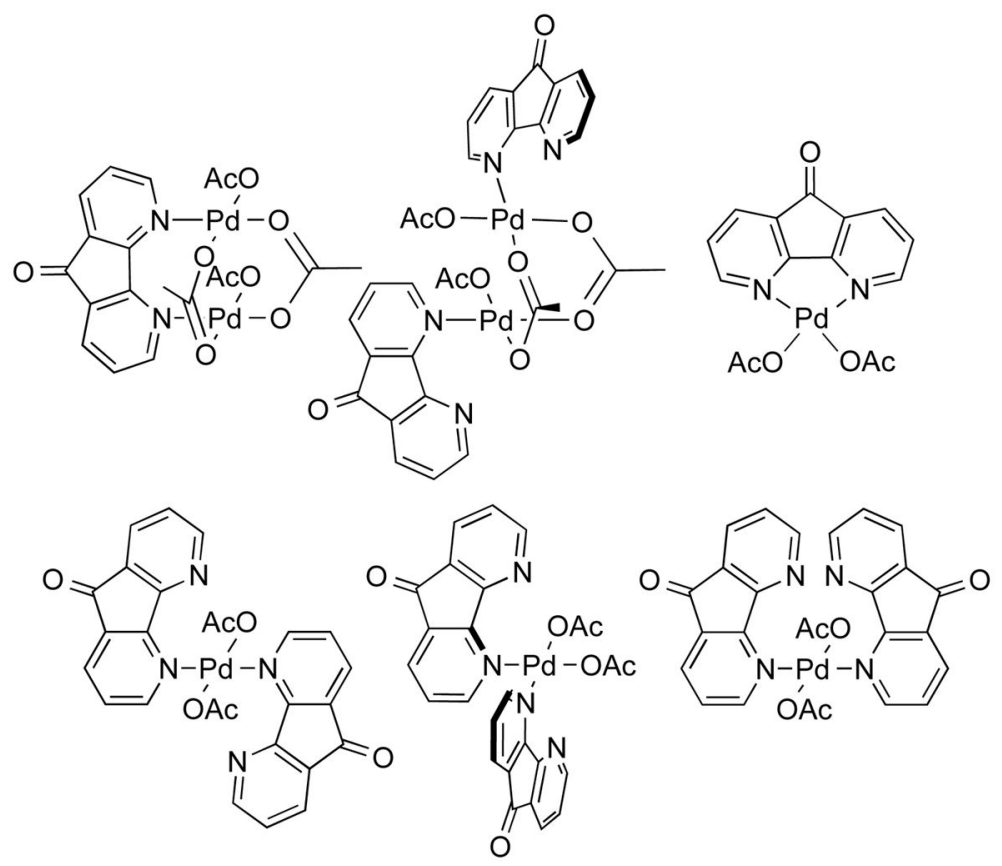

Chart 1.

Structures Present in a 1:1 Solution of DAF and $\mathrm{Pd}(\mathrm{OAc})_{2}{ }^{22}$ 
Table 1

Assessment of Bidentate Ligands on Oxidative Amidation ${ }^{a}$

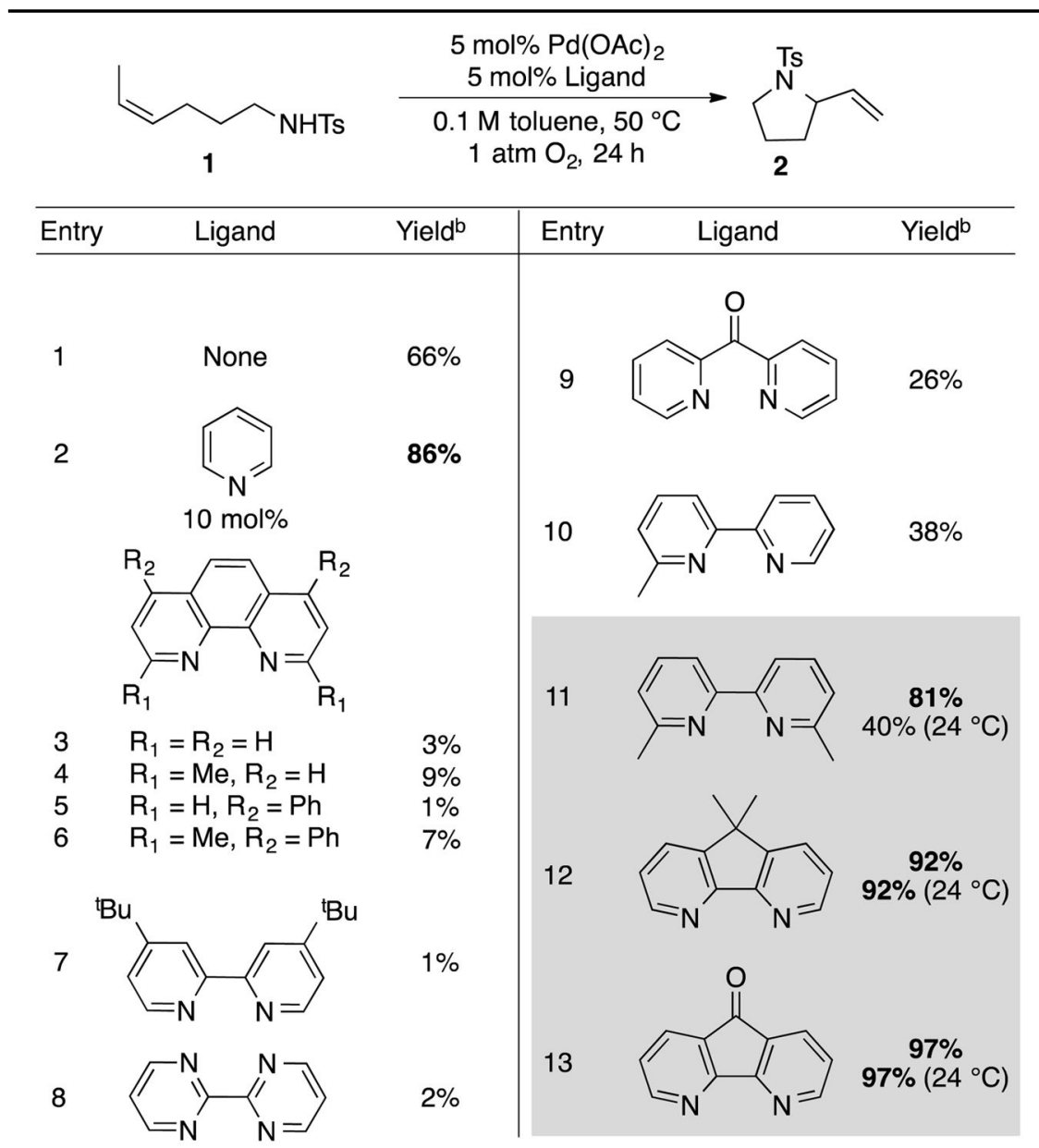

${ }^{a}$ Conditions: substrate $(75 \mu \mathrm{mol}, 0.1 \mathrm{M}), \mathrm{Pd}(\mathrm{OAc}) 2(3.75 \mu \mathrm{mol}), \mathrm{O}_{2}(1 \mathrm{~atm})$, toluene $(0.75 \mathrm{~mL}), 50^{\circ} \mathrm{C}, 24 \mathrm{~h}$.

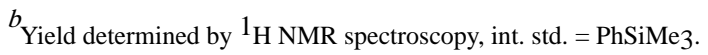




\section{Table 2}

Relative Ligand Binding Strength of Bidentate Ligands Relative to Pyridine.
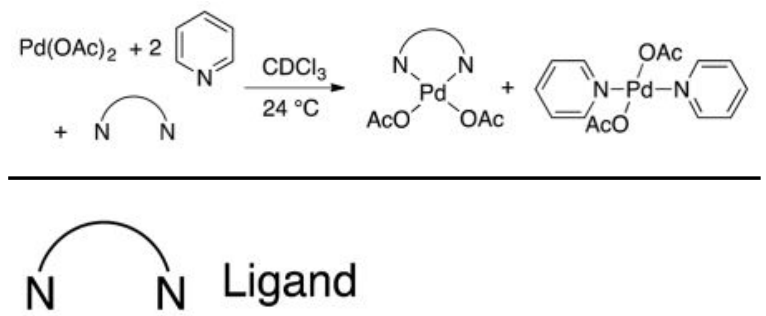

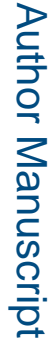

$(\mathrm{N} \sim \mathrm{N}) \operatorname{Pd}(\mathrm{OAc})_{2}: \operatorname{Pd}(\mathrm{py})_{2}(\mathrm{OAc})_{2}$

\begin{tabular}{cc}
\hline 4,4'-'-Bu & bpy \\
$2,9-\mathrm{Me}_{2}$ phen & $40: 1$ \\
$6,6 '-\mathrm{Me}_{2}$ bpy & $5: 1$ \\
DAF & $1: 4.3$ \\
\hline
\end{tabular}

${ }^{a}$ The DAF ligated species is $\mathrm{Pd}\left(\kappa^{1}-\mathrm{DAF}\right)(\mathrm{py})(\mathrm{OAc}) 2$, not $\mathrm{Pd}\left(\kappa^{2}-\mathrm{DAF}\right)(\mathrm{OAc}) 2$.

See Figure 5 and text for details 